\title{
TUMPAH TINDIH DALAM PROSES PERIZINAN KLINIK PRATAMA DI DINAS PENANAMAN MODAL DAN PELAYANAN TERPADU SATU PINTU KOTA PADANG
}

\author{
${ }^{1}$ Delfina Gusman, ${ }^{2}$ Marryo Borry WD \\ ${ }^{1}$ Fakultas Ilmu Hukum, Universitas Andalas \\ ${ }^{2}$ Fakultas Kedokteran, Universitas Andalas
}

\begin{abstract}
Clinics are health care facilities that provide individual health services that provide basic medical and / or specialist services. Primary Clinic is a clinic that provides basic medical services both general and special. To establish primary clinics until they can operate through a series of licensing processes, namely the Hinder Ordonnantie (HO) Permit, Clinical Establishment Permit (IMK) and Clinical Operational Permit (IOK). The results of the process are overlapping or suggesting requirements that make the process ineffective and inefficient.
\end{abstract}

Keywords: Licensing, Primary Clinic, Disruption Permit, Clinic Establishment Permit, Clinic Operational Permit

\section{PENDAHULUAN}

Menurut Permenkes Nomor 9 Tahun 2014 Klinik didefinisikan sebagai fasilitas pelayanan kesehatan yang menyelenggarakan pelayanan kesehatan perorangan yang menyediakan pelayanan medis dasar dan/atau spesialistik. Klinik terbagi dua yaitu klinik pratama dan klinik futama. Klinik pratama adalah klinik yang menyelenggarakan pelayanan medik dasar baik umum maupun khusus. Sedangkan klinik utama adalah klinik yang menyelenggarakan pelayanan medik spesialistik atau pelayanan medik dasar dan spesialistik. Klinik pratama melaksanakan pelayanan medis dasar yaitu pelayanan dokter umum, dokter gigi umum, pelayanan obat-obatan, pelayanan laboratorium sederhana.
Dalam hal kelengkapan sarana dan prasaranan serta sumber daya manusia sesuai dengan Permenkes Nomor 9 Tahun 2014 tentang klinik. Ketenagaan Klinik rawat jalan terdiri atas tenaga medis, tenaga keperawatan, tenaga kesehatan lain, dan tenaga non kesehatan sesuai dengan kebutuhan. Untuk klinik pratama tenaga medis pada Klinik pratama yang memberikan pelayanan kedokteran paling sedikit terdiri dari 2 (dua) orang dokter dan/atau dokter gigi sebagai pemberi pelayanan. Jenis, kualifikasi, dan jumlah Tenaga Kesehatan lain serta tenaga non kesehatan disesuaikan dengan kebutuhan dan jenis pelayanan yang diberikan oleh Klinik. Setiap tenaga medis yang berpraktik di Klinik harus mempunyai Surat Tanda Registrasi (STR) dan Surat Izin 
Praktik (SIP) sesuai ketentuan peraturan perundang-undangan.

Klinik harus dilengkapi dengan peralatan medis dan nonmedis yang memadai sesuai dengan jenis pelayanan yang diberikan. Peralatan medis dan nonmedis harus memenuhi standar mutu, keamanan, dan keselamatan.

Bangunan Klinik harus bersifat permanen dan tidak bergabung fisik bangunannya dengan tempat tinggal perorangan. Ketentuan tempat tinggal tidak termasuk apartemen, rumah toko, rumah kantor, rumah susun, dan bangunan yang sejenis. Bangunan Klinik harus memperhatikan fungsi, keamanan, kenyamanan dan kemudahan dalam pemberian pelayanan serta perlindungan keselamatan dan kesehatan bagi semua orang termasuk penyandang cacat, anak-anak dan orang usia lanjut.

Bangunan Klinik paling sedikit terdiri atas ruang pendaftaran/ruang tunggu, ruang konsultasi, ruang administrasi, ruang obat dan bahan habis pakai untuk klinik yang melaksanakan pelayanan farmasi, ruang tindakan, ruang/pojok ASI, kamar mandi/wc, ruangan lainnya sesuai kebutuhan pelayanan.

Untuk mendapatkan izin, sebuah klinik harus melalui serangkaian proses perizinan. Proses tersebut yaitu izin gangguan, izin mendirikan, dan izin operasional. Seluruh perizinan tersebut dilakukan di Dinas Penanaman Modal dan Pelayanan Terpadu
Satu Pintu. Di Kota Padang seluruh perizinan sudah di laksanakan di Dinas Penanaman Modal dan Pelayanan Terpadu Satu Pintu. Namun dalam perizinan tersebut beberapa persyaratan saling beririsan/tumpang tindih yang menyebabkan pengulangan setiap mengajukan perizinan. Untuk itu penulis ingin membahas tentang tumpang tindih perizinan klinik.

Tujuan Penelitian ini bertujuan untuk menganalisis dan mereview tentang perizinan klinik, menganalisis regulasi perizinan di tingkat Kota Padang sebagai dasar bagi rekomendasi penyederhanaan, penghapusan dan penggabungan perizinan oleh Pemerintah Kota Padang.

Manfaat penelitian ini diharapkan dapat memberikan manfaat yaitu menjadi bahan rekomendasi bagi pemerintah daerah dalam melakukan regulasi perizinan, sebagai bahan advokasi pelaku usaha maupun masyarakat kepada para pemangku kebijakan di daerah untuk melakukan perbaikan di bidang perizinan usaha.

\section{METODE PENELITIAN}

Penelitian ini merupakan penelitian deskriptif analitis, yaitu penelitian yang menggambarkan data secara jelas dan teliti yang kemudian dengan data tersebut dianalisis permasalahan yang ada serta dicari penyelesaiannya berdasarkan peraturan perundang-undangan dan peraturan lainnya yang memiliki relevansi dengan penelitian. 
Pendekatan utama yang digunakan dalam penelitian ini adalah pendekatan yuridis normatif. Menurut Ronny Hanitijo Soemitro pendekatan penelitian hukum normatif dilakukan dengan cara penelitian terhadap inventarisasi hukum positif, penelitian terhadap asas-asas hukum, penelitian terhadap sistematika hukum serta penelitian terhadap taraf sinkronisasi peraturan perundang-undangan, baik secara vertikal maupun secara horizontal. ${ }^{1}$

Sedangkan sebagai pendukung pendekatan utama digunakan pendekatan yuridis empiris, yaitu suatu penelitian yang mengkonsepkan hukum sebagai gejala empiris yang dapat diamati dalam kehidupan. ${ }^{2}$ Yang dilakukan dengan cara mengumpulkan semua data yang diperoleh dari lapangan yang berhubungan erat dengan permasalahan penelitian. Data yang digunakan dalam penelitian ini terdiri atas data primer (primary data) dan data sekunder (secondary data)yang bersumber dari bahan hukum primer, bahan hukum sekunder dan bahan hukum tersier. ${ }^{3}$ Untuk memperoleh data sekunder, dikumpulkan dengan cara melakukan penelitian kepustakaan (library research). Sedangkan untuk memperoleh data primer,

\footnotetext{
1 Ronny Hanitijo Soemitro, Metodologi Penelitian Hukum dan Jurimetri, GhaliaIndonesia, Jakarta, 1998, hlm.11-33

${ }^{2}$ Bambang Sunggono, Metodologi Penelitian Hukum, Rajawali Pers, Jakarta,2003,hlm.27

3 Soerjono Soekanto, Pengantar Penelitian Hukum, UIPress, Jakarta, 1986, hlm. 51-52
}

dikumpulkan dengan cara melakukan penelitian lapangan (field research). Data yang diperoleh dari hasil penelitian dianalisis secaram kualitatif, yaitu dengan memberikan komentar-komentar dan tidak menggunakan angka-angka.

Analisis kualitatif menurut Lexy J. Moleong, merupakan upaya yang dilakukan dengan jalan bekerja dengan data, mengorganisasikan data, memilah-milahnya menjadi suatu yang dapat dikelola, mensintesiskannya, mencari dan menemukan pola, menemukan apa yang penting dan apa yang dipelajari, dan memutuskan apa yang dapat diceritakan kepada orang lain. ${ }^{4}$

Data yang telah dianalis secara kualitatif, kemudian disajikan dalam bentuk deskriptif analitis, yaitu hanya akan menggambarkan saja dari hasil penelitian secara jelas dan teliti, yang berhubungan dengan pokok permasalahan penelitian.

\section{PEMBAHASAN}

\section{Perizinan untuk Izin Klinik Pratama}

Klinik Pratama harus memngikuti serangkaian proses yaitu pengurusan izin gangguan/ Izin gangguan/ Hinder Ordonnantie $(\mathrm{HO})$, izin mendikian klinik (IMK) dan izin operasional klinik ( IOK).

\footnotetext{
${ }^{4}$ Lexy J. Moleong, Metodologi Penelitian Kualitatif, Remaja Rosdakarya, Bandung, 2005, hlm. 248.
} 
1. Izin gangguan/ Hinder Ordonnantie (HO)

Berdasarkan Perwako Nomor 9 tahun 2016 tentang tata cara pemberian, pembinaan, dan pengawasan Izin gangguan/ Hinder Ordonnantie (HO) adalah pemberian izin tempat usaha/ kegiatan kepada orang pribadi atau badan usaha di lokasi tertentu yang dapat menimbulkan bahaya, kerugian, dan gangguan tidak termasuk tempat usaha/ kegiatan yang telah di tentukan oleh pemerintah pusat, pemerintah daerah, atau pemerintah kota padang sesuai peraturan perundang-undangan. Untuk mengajukan permohonan, pemohon harus mengajukan permohonan tertulis kepada Walikota Padang dengan mengisi formulir yang telah disediakan di Dinas Penanaman Modal dan Pelayanan Terpadu Satu Pintu secara lengkap dan benar dengan melengkapi persyaratan sebagai berikut :

a. Foto kopi kepemilikan atau penguasaan tanah dan atau bangunan.

b. Foto kopi izin mendirikan bangunan atau surat keterangan izin mendirikan bangunan yang dilegalisir, di kecualikan bagi tempat usaha di ruang terbuka (tidak ada bangunan), bangunan cagar budaya, dan banguanan yang sudah berumur 25 (dua puluh lima ) tahun.

c. Untuk status tempat yang di sewa dimana poin a dan $b$ tidak dapat dilampirkan, maka diperlukan surat perjanjian kontrak antara sipemilik banguanan dan sipenyewa dengan materai 6000.- atau dengan akte swa menyewa yang di ketahui oleh notaris dan dilegalisir.

d. Foto kopi kartu tanda penduduk atau kartu tanda pengenal lainnya yang masih berlaku.

e. Foto kopi akta pendirian usaha/ lembaga yang dilegalisir.

f. Melampirkan surat keputusan pengesahan badan usaha dari instansi yang berwenang bagi badan usaha yang dilegalisir.

g. Melampirkan bukti terdaftar dari instansi yang berwenang yang dilegalisir.

h. Pas foto ukuran $3 \times 4$ sebanyak 2 (dua) lembar.

i. Dokumen kelayakan lingkungan sesuai peraturan perundang-undangan.

j. Skema/denah lokasi usaha foto tempat usaha dan bangunan dari 3 (tiga) sisi berbeda.

k. Surat persetujuan tetangga yang dilampirkan dengan foto kopi kartu tanda penduduk diketahui RT/RW/ lurah setempat.

2. Izin mendirikan klinik (IMK)

Permohonan izin mendirikan klinik (IMK) di buat oleh Dinas Penanaman Modal dan Pelayan Terpadu Satu Pintu berdasarkan Permenkes Nomor 9 tahun 2014 dengan persyaratan : 
a. Identitas lengkap pemohon.

b. Salinan/fotokopi pendirian badan hukum atau badan usaha, kecuali untuk kepemilikan perorangan.

c. Salinan/fotokopi yang sah sertifikat tanah, bukti kepemilikan lain yang disahkan oleh notaris, atau bukti surat kontrak minimal untuk jangka waktu 5 (lima) tahun. Dokumen SPPL untuk Klinik rawat jalan, atau dokumen UKL-UPL untuk Klinik rawat inap sesuai ketentuan peraturan perundangundangan.

d. Profil Klinik yang akan didirikan meliputi pengorganisasian, lokasi, bangunan, prasarana, ketenagaan, peralatan, kefarmasian, laboratorium, serta pelayanan yang diberikan.

e. Persyaratan lainnya sesuai dengan peraturan daerah setempat

Persyaratan tambahan yang dibuat oleh Pemerintah Kota Padang yaitu :

a. Rekomendasi dari Dinas Kesehatan Kota Padang. Untuk mendapatkan rekomendasi, pemohon melampirkan Profil Klinik yang akan didirikan meliputi pengorganisasian, lokasi, bangunan, prasarana, ketenagaan, peralatan, kefarmasian, laboratorium, serta pelayanan yang diberikan.

b. Izin prinsip (dari Bappeda).

c. Izin Gangguan.

d. Izin mendirikan bangunan (IMB) e. Surat persyaratan keabsahan dokumen (bermaterai 6000,-)

3. Izin operasional klinik (IOK)

Permohonan izin operasional klinik (IOK) di buat oleh Dinas Penanaman Modal dan Pelayan Terpadu Satu Pintu berdasarkan Permenkes Nomor 9 tahun 2014 dengan persyaratan :

1. Persyaratan teknis meliputi persyaratan lokasi, bangunan, prasarana, ketenagaan, peralatan, kefarmasian, dan laboratorium.

m. Persyaratan administrasi meliputi izin mendirikan dan rekomendasi dari dinas kesehatan kabupaten/kota Persyaratan tambahan dari Pemerintah Kota Padang :

a. Rekomendasi dari Dinas Kesehatan Kota Padang.

b. Fotokopi izin gangguan.

c. Dokumen SPPL untuk klinik pratama.

d. Curiculum Vitae penanggung jawab/ pimpinan.

e. Data kelengkapan peralatan medik dan non medik.

f. Daftar ketenagaan dan struktur organisasi pelayanan yang di uraiakan dalam pembagian tugas dan di sertakan dengan foto kopi STR, SIP, STRA, SIPA, SIK, dan ijazah ( Dokter min. 2 orang, perawat min 2 orang ).

g. Denah lokasi dan Ruangan.

h. Surat pernyataan penanggung jawab untuk membuat laporan. 
i. Hasil pemeriksaan air bersih minimal 6 bulan teakhir

j. MOU pembuangan sampah medis.

k. Pas foto ukuran $3 \times 4$ sebanyak 3 lembar.

1. Materai 6000 sebanyak 1 lembar.

m. Jenis pelayanan dan jadwal pelayanan.

n. MUO untuk pemeriksaan labor.

o. Jenis pelayanan yang diberikan.

p. Foto kopi KTP dan NPWP Pemohon.

q. Surat pernyataan keabsahan dokumen (bermaterai 6000)

\section{Analisis Perizinan Klinik Di Kota Padang}

Kelengkapan Dokumen Izin Gangguan/

\section{Hinder Ordonnantie (HO)}

Berdasarkan Perwako Nomor 9 tahun 2016 tentang tata cara pemberian, pembinaan, dan pengawasan Izin gangguan/

Hinder Ordonnantie ( $\mathrm{HO})$.

1. Foto kopi kepemilikan atau penguasaan tanah dan atau bangunan.

2. Foto kopi izin mendirikan bangunan atau surat keterangan izin mendirikan bangunan yang dilegalisir

3. Untuk status tempat yang di sewa dimana poin a dan b tidak dapat dilampirkan, maka diperlukan surat perjanjian kontrak.

4. Foto kopi kartu tanda penduduk atau kartu tanda pengenal lainnya yang masih berlaku.

5. Foto kopi akta pendirian usaha/ lembaga yang dilegalisir.
6. Surat keputusan pengesahan badan usaha dari instansi yang berwenang bagi badan usaha yang dilegalisir.

7. Bukti terdaftar dari instansi yang berwenang yang dilegalisir.

8. Pas foto ukuran $3 \times 4$ sebanyak 2 (dua) lembar.

9. Dokumen kelayakan lingkungan sesuai peraturan perundang-undangan.

10.Skema/denah lokasi usaha foto tempat usaha dan bangunan dari 3 (tiga) sisi berbeda.

11.Surat persetujuan tetangga yang dilampirkan dengan foto kopi kartu tanda penduduk diketahui RT/RW/ lurah setempat.

\section{Kelengkapan Dokumen Izin mendirikan} klinik (IMK)

1. Identitas lengkap pemohon.

2. Salinan/fotokopi pendirian badan hukum atau badan usaha, kecuali untuk kepemilikan perorangan.

3. Salinan/fotokopi yang sah sertifikat tanah, bukti kepemilikan lain yang disahkan oleh notaris, atau bukti surat kontrak minimal untuk jangka waktu 5 (lima) tahun.

4. Dokumen SPPL untuk Klinik rawat jalan, atau dokumen UKL-UPL untuk Klinik rawat inap sesuai ketentuan peraturan perundangundangan.

5. Profil Klinik yang akan didirikan meliputi pengorganisasian, lokasi, bangunan, prasarana, ketenagaan, peralatan, 
kefarmasian, laboratorium, serta pelayanan yang diberikan.

6. Persyaratan lainnya sesuai dengan peraturan daerah setempat

Persyaratan tambahan yang dibuat oleh Pemerintah Kota Padang yaitu :

1. Rekomendasi dari Dinas Kesehatan Kota Padang. Untuk mendapatkan rekomendasi, pemohon melampirkan Profil Klinik yang akan didirikan meliputi pengorganisasian, lokasi, bangunan, prasarana, ketenagaan, peralatan, kefarmasian, laboratorium, serta pelayanan yang diberikan.

2. Izin prinsip (dari Bappeda).

3. Izin Gangguan.

4. Izin mendirikan bangunan (IMB).

5. Surat persyaratan keabsahan dokumen (bermaterai 6000,-)

\section{Kelengkapan Dokumen Izin operasional klinik (IOK)}

1. Persyaratan teknis meliputi persyaratan lokasi, bangunan, prasarana, ketenagaan, peralatan, kefarmasian, dan laboratorium

2. Persyaratan administrasi meliputi izin mendirikan dan rekomendasi dari dinas kesehatan kabupaten/kota

Persyaratan tambahan dari Pemerintah

Kota Padang :

1. Rekomendasi dari Dinas Kesehatan Kota Padang.

2. Foto kopi izin gangguan.

3. Dokumen SPPL untuk klinik pratama.
4. Curiculum Vitae penanggung jawab/ pimpinan.

5. Data kelengkapan peralatan medik dan non medik.

6. Daftar ketenagaan dan struktur organisasi pelayanan yang di uraiakan dalam pembagian tugas dan di sertakan dengan foto kopi STR, SIP, STRA, SIPA, SIK, dan ijazah ( Dokter min. 2 orang, perawat $\min 2$ orang ).

7. Denah lokasi dan Ruangan.

8. Surat pernyataan penanggung jawab untuk membuat laporan.

9. Hasil pemeriksaan air bersih minimal 6 bulan teakhir.

10.MOU pembuangan sampah medis.

11.Pas foto ukuran $3 \times 4$ sebanyak 3 lembar.

12.Materai 6000 sebanyak 1 lembar.

13.Jenis pelayanan dan jadwal pelayanan.

14.MUO yntuk pemeriksaan labor.

15.Jenis pelayanan yang diberikan.

16.Foto kopi KTP dan NPWP Pemohon.

17.Surat pernyataan keabsahan dokumen (bermaterai 6000)

\section{Irisan/ tumpang tindih dari proses perizinan klinik pratama}

Merujuk pada Permenkes nomor 9 tahun 2014 tentang klinik yang mengatur tentang izin mendirikan klinik dan izin operasional klinik dan Perwako nomor 9 tahun 2016 Perwako Nomor 9 tahun 2016 tentang tata cara pemberian, pembinaan, dan pengawasan Izin gangguan/ Hinder Ordonnantie (HO) serta aturan tambahan 
yang di buat oleh Pemerintah Kota Padang ada bebeberapa irizan/tumpang tindih dalam proses tersebut :

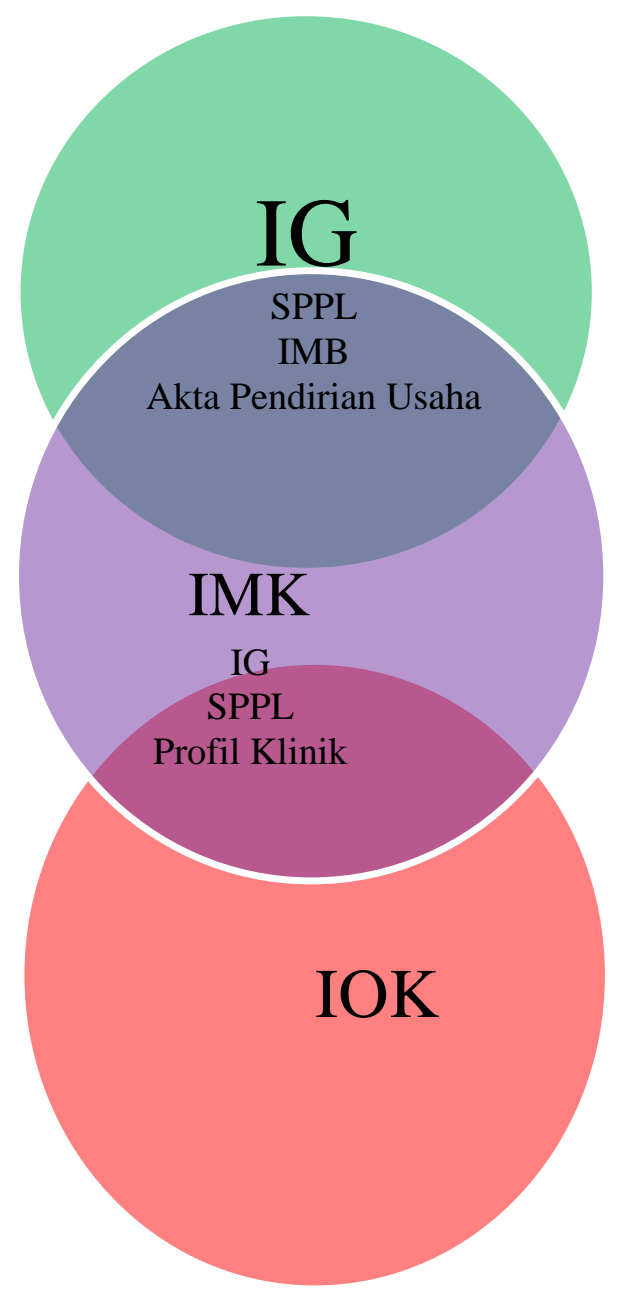

Dari bagan tersebut terlihat adanya pengulangan dari persyaratan yang harus di lengkapi oleh pemohon kepada Dinas Penanaman Modal dan Pelayanan Terpadu satu Pintu Kota Padang. Ketika pemohon mengajukan permohonan pengurusan izin mendirikan Klinik pemohon harus melengkapi izin gangguan, izin mendirikan bangunan, dan SPPL. Padahal syarat untuk pembuatan izin gangguan harus ada SPPL dan izin mendirikan bangunan. Terlihat adanya tumpang tindih dalam perizinan yang di buat pemerintah.

Pada pengurusan izin operasional klinik, pemohon harus melengkapi izin gangguan, SPPL, Akta pendirian, Profil klinik. Syarat tersebut sudah di minta sewaktu pengurusan izin mendirikan klinik. Pada pengurusan inipun terlihat adanya tumpang tindih dalam hal persayaratan yang dibuat oleh Pemerintah.

\section{PENUTUP}

Membuat sebuah klinik Pratama tidak mudah, harus mengikuti serangkaian proses yang harus di lewati yang di buat oleh pemerintah. Proses itu adalah pembuatan izin gangguan, izin mendirikan klinik, izin operasioanl klinik. Namun proses tersebut menjadi tidak efisien dan tidak efektif karena adanya pengulangan syarat yang di buat oleh pemerintah. Padahal syarat tersebut sudah masuk dalam izin sebelumnya.

Untuk itu perlu ada deregulasi dari peraturan yang di buat oleh pemerintah Kota Padang untuk perizinan klinik Pratama. Perlu pengkajian ulang agar pelayanan perizinan menjadi lebih efektif dan efisien. Revisi persayaratan yang dibuat oleh pemerintah Kota Padang melalui Dinas Penanaman Modal dan Pelayanan TerpaduSatu Pintu dan bekerja sama dengan Dinas Kesehatan dan Dinas terkait. 


\section{DAFTAR PUSTAKA}

\section{Buku}

Ronny Hanitijo Soemitro, Metodologi Penelitian Hukum dan Jurimetri, GhaliaIndonesia, Jakarta, 1998, hlm.11-33

Bambang Sunggono, Metodologi Penelitian Hukum, Rajawali Pers, Jakarta,2003,hlm.27

Soerjono Soekanto, Pengantar Penelitian Hukum, UIPress, Jakarta, 1986, hlm. 51-52

Lexy J. Moleong, Metodologi Penelitian Kualitatif, Remaja Rosdakarya, Bandung, 2005, hlm. 248.

S.JU.Fockema Andreae, 1951, Rechtsgeleerd Handwoordenboek, Tweede Druk, J.B. Wolter' Uitgevers-maatshappij N.V., Groningen, h.311.

E. Utrecht, 1988, Pengantar Hukum Administrasi Negara Indonesia , Pustaka Tinta Mas, Surabaya, h.187.

N.M. Spelt dan J.BJ.M.ten Berge, 1993, Pengantar Hukum Perizinan, disunting oleh Philipus M. Hadjon, Yuridika, Surabaya, h.2-3.

Bagir Manan, 1995, Ketentuan-Ketentuan Mengenai Pengaturan Penyelenggaraan Hak Kemerdekaan Berkumpul Ditinjau Dari Perspektif UUD 1945, Makalah, Tidak Dipublikasikan, Jakarta, h.8.

Philipus M. Hadjon, et.al., 1993, Pengantar Hukum Administrasi Indonesia, Gadjah Mada University Press, Yogyakarta, h.125.

C.J.N. Versteden, 1984, Inleiding Algemeen Bestuursrecht. Samsom H.D.Tjeenk Willink, Alphen aan den Rijn, h.69.

Marcus Lukman, 1996, Eksistensi Peraturan Kebijaksanaan Dalam Bidang Perencanaan dan Pelaksanaan Rencana Pembangunan di Daerah serta Dampaknya terhadap Pembangunan
Materi Hukum Tertulis Nasional, Disertasi, Universitas Padjadjaran, Bandung, h.189.

Sjachran Basah, 1996, Sister Perizinan Sebagai Instrumen Pengendali Lingkungan, Makalah Pada Seminar Hukum Lingkungan, Diselenggarakan Oleh KLH bekerja sama dengan Legal Mandate Compliance end Enforcement Program dari BAPEDAL, Jakarta, h.189.

N.M.Spelt dan J.B.J.M. ten Berge, op.cit, h.11.

Soehardjo, 1991, Hukum Administrasi Negara Pokok-Pokok Pengertian Serta Perkembangannya di Indonesia, Badan Penerbit Universitas Diponegoro, Semarang, h.25.

Ridwan HR, op.cit, h.206.

Soehino, 1984, Asas-Asas Hukum Tata Pemerintahan, Liberty, Yogyakarta, h. 97.

Sri Pudyatmoko, 2009, Perizinan : Problem dan Upaya Pembenahan

\section{Peraturan Perundang-undangan}

Undang-Undang Dasar Tahun1945

Permenkes Nomor 9 Tahun 2014 Tentang Klinik

Permendagri No.20 Tahun 2008 tentang Pedoman Organisasi dan Tata Kerja Unit Pelayanan Perizinan Terpadu di Daerah

Peraturan Walikota Padang Nomor 9 Tahun 2016 Tentang Tata Cara Pemberian, Pembinaan, dan Pengawasan Izin Gangguan

Peraturan Daerah Kota Padang Nomor 5 Tahun 2016 Tentang Izin Gangguan

Peraturan Walikota Padang Nomor 107 Tahun 2016 Tentang Peraturan Pelaksanaan Peraturan Daerah Kota Padang Nomor 5 Tahun 2016 Tentang Izin Gangguan 